\title{
Joule per Kilogram-Kelvin
}

National Cancer Institute

\section{Source}

National Cancer Institute. Joule per Kilogram-Kelvin. NCI Thesaurus. Code C70451.

A SI unit of specific entropy. 